REGARDS

SUR LEECONOMIE ALLEMANDE

BULLETIN ECONOMIQUE DU CRAC

\section{Regards sur l'économie allemande}

Bulletin économique du CIRAC

$97 \mid 2010$

Varia

\title{
Travail : fin de la convention unique de branche
}

Isabelle Bourgeois

\section{OpenEdition}

Journals

Édition électronique

URL : http://journals.openedition.org/rea/4137

DOI : 10.4000/rea.4137

ISBN : 978-2-8218-0890-4

ISSN : 1965-0787

Éditeur

CIRAC

Édition imprimée

Date de publication : 1 juillet 2010

Pagination : 31

ISSN : 1156-8992

Référence électronique

Isabelle Bourgeois, "Travail : fin de la convention unique de branche », Regards sur l'économie allemande [En ligne], 97 | juillet 2010, mis en ligne le 13 juillet 2010, consulté le 15 septembre 2020. URL : http://journals.openedition.org/rea/4137

Ce document a été généré automatiquement le 15 septembre 2020

(C) CIRAC 


\title{
Travail : fin de la convention unique de branche
}

\author{
Isabelle Bourgeois
}

\section{Désormais, pluralisme des conventions dans l'entreprise}

1 Le Tribunal fédéral du Travail (Erfurt) vient de reléguer dans le fonds de l'Histoire un principe au fondement du modèle économique et social allemand d'après-guerre : une entreprise, une convention tarifaire de branche. Il estime en effet " qu'il n'existe pas de principe supérieur qui exigerait que, dans une entreprise, les différents emplois d'un même type ne puissent être régis que par des conventions tarifaires uniques " (communiqué $\mathrm{n}^{\circ} 46 / 10$; www.bundesarbeitsgericht.de). Dorénavant, le principe qui s'applique est celui du pluralisme des conventions tarifaires dans l'entreprise.

2 Dans une décision rendue le 23 juin (10 AS 2/10 et 10 AS 3/10), la dixième chambre de cette cour a confirmé l'analyse que lui avait soumise la quatrième chambre le 27 janvier 2010 (1 AZR 537/08 (A) et 4 AZR 549/08 (A)). Celle-ci ne pouvait en effet pas remettre seule en cause la jurisprudence développée par la Cour au fil des décennies. Car le principe de la convention unique de branche (Tarifeinheit) ne repose sur aucune loi ; il était né de l'interprétation faite par les juges de la Loi sur les conventions tarifaires de branche (Tarifvertragsgesetz, TVG).

\section{La mutation des activités avait remis en question la justification du principe de la convention unique de branche}

3 Or ce principe était de plus en plus controversé ces dernières années. Sous l'effet des mutations de l'économie, le périmètre des branches s'était dilué, ce qui pose depuis, d'une part le problème des critères déterminant l'appartenance de telle ou telle 
entreprise à telle ou telle branche; d'autre part, le problème de la délimitation des compétences entre les différents syndicats (ou fédérations patronales) œuvrant dans une 'branche' aux contours de plus en plus flous. Dans le fil de la tertiarisation de l'économie, à laquelle le conglomérat des services ver.di avait tenté d'apporter une réponse organisationnelle en se constituant comme représentant unique du secteur des services - mais sans représentant patronal unique lui faisant pendant -, on avait vu se multiplier les syndicats catégoriels. Cette tendance est particulièrement nette dans le domaine des anciens services publics en voie de libéralisation où on a vu naître des associations de pilotes (Cockpit) ou de conducteurs de trains (GDL; voir REA 83/07). Ces évolutions avaient fini par soulever une question de fond : le principe de la convention unique de branche est-il compatible avec le principe constitutionnel du libre choix de la représentation conventionnelle (Tariffreiheit)? Et ne discrimine-t-il pas ces petites organisations, parmi lesquelles les syndicats chrétiens (280 000 adhérents) ?

Le Tribunal fédéral du Travail n'avait pas à statuer sur ces questions qui préoccupent les experts et juristes du travail, mais à trancher dans le cas concret d'un médecin hospitalier auquel s'appliquaient deux conventions : celle des salariés de la fonction publique (BAT) et celle, catégorielle, des médecins du secteur public (Marburger Bund). Dorénavant, cette situation est considérée comme légale.

\section{Un syndicalisme de plus en plus émietté}

5 La décision inquiète au plus haut point fédérations syndicales et patronales qui cherchent, ensemble, à trouver une issue à cette situation. Le patronat redoute en effet que la concurrence avivée entre les syndicats qu'induit le nouveau pluralisme de leur représentativité ne scelle la fin de la paix sociale dans les entreprises. Le DGB redoute, quant à lui, la fin de ce que le quotidien F.A.Z. résume sous le terme de "monopole» (29-01-10). Or ce monopole est fragilisé par la baisse du taux d'organisation: le DGB ne compte plus que 6,26 millions de membres (2009), dont 2,26 millions sont affiliés à IG Metall et 2,14 à ver.di (IGBCE vient en troisième position avec un peu moins de 0,9 million d'adhérents). Les organisations catégorielles sont loin d'atteindre ces volumes, mais leur influence est en hausse, et ils ont un fort pouvoir de nuisance. La plus importante est le Marburger Bund, avec 108000 membres, suivi par les syndicats des conducteurs de train (GDL, 34 000), des hôtesses de l'air (UFO, 10 000), des pilotes (Cockpit, 8 200) et des contrôleurs aériens (GdF, 3 000).

\section{Les partenaires sociaux en quête d'une nouvelle régulation}

6 Partenaires sociaux et gouvernement cherchent activement à développer une nouvelle régulation des relations du travail au sein de l'entreprise. Le DGB et ses partenaires patronaux (BDA et BDI) réfléchissent à une révision de la Loi TVG, pour y inscrire notamment une règle de représentativité syndicale pour encadrer la nouvelle concurrence syndicale. La tâche est épineuse, car toute solution législative doit respecter le principe constitutionnel de l'autonomie tarifaire des partenaires sociaux. A suivre... 
INDEX

Mots-clés : marché du travail, entreprise, salarié, syndicat, syndicalisation, négociation collective, représentation du personnel, convention d'entreprise, comité d'entreprise, Betriebsrat, conditions de travail, partenaires sociaux, DGB 